\title{
Human chromosomal heteromorphisms in American blacks. VI. Higher incidence of longer Y owing to non-fluorescent (nf) segment*
}

\author{
RAM S VERMA, MARCIA EVANS-MCCALLA, AND HARVEY DOSIK \\ From the Divisions of Cytogenetics and Hematology, The Jewish Hospital and Medical Center of \\ Brooklyn, and Department of Medicine, State University of New York, Downstate Medical Center, \\ Brooklyn, New York, USA.
}

SUMMARY Sixty normal male American blacks were selected to study the length of fluorescent (f), non-fluorescent (nf), and total length of the Y chromosome by the QFQ technique. The length of the $\mathrm{Y}$ chromosome was classified into five groups: very small, small, average, large, and very large. The frequencies of $\mathrm{Y} / \mathrm{F}$ indices for these groups were $0 \cdot 0,3 \cdot 33,56 \cdot 67,30 \cdot 00$, and $10 \cdot 00 \%$, respectively. The variation in the total length of the $\mathrm{Y}$ chromosome was accounted for by variations in the length of the $\mathrm{nf}$ as well as the $\mathrm{f}$ segment. A longer $\mathrm{Y}$ was noted in blacks owing to an increase in size of the nf segment in comparison with a normal Caucasian population. Forty percent of American blacks had large or very large Y chromosomes, while this class comprised only $18 \cdot 3 \%$ of Caucasians, which is significantly different $(p<0.05)$. Furthermore, the length of the $Y$ chromosome was normally distributed among Caucasians, while among blacks the distribution was skewed to the left. The mean $\mathrm{Y} / \mathrm{F}, \mathrm{f} / \mathrm{F}$, and $\mathrm{nf} / \mathrm{F}$ indices were $1.09 \pm 0 \cdot 10,0.42 \pm 0.09$, and $0.67 \pm 0.04$, respectively.

The length variation (heteromorphisms) of the long arm of the $\mathrm{Y}$ chromosome is a well established fact, ${ }^{12}$ and by family studies it has been concluded that the $Y$ chromosome is inherited at a constant length..$^{3-8}$ The variation in the length of the $Y$ chromosome has previously been reported to be largely because of the fluorescent (f) segment of the long arm, while the non-fluorescent (nf) segment is relatively stable. $^{9-13}$ Nevertheless, there are at least three studies, including one of our own, indicating that the $n$ f segment does contribute to the variation in $Y$ chromosome length. ${ }^{14-16}$ Before the banding era, racial variation in the length of the human $Y$ chromosome was demonstrated by Cohen $e t$ al $^{17}$ by conventional staining. Since it is now an accepted fact that the nf segment is also heteromorphic, we have employed the QFQ technique ( $Q$ bands by fluorescence using quinacrine as suggested by $\mathrm{ISCN}^{18}$ ) on 60 Caucasians and 60 American blacks

\footnotetext{
* Supported by the National Cancer Institute Contract No N01-CP43251. MEM was a summer research fellow at the Jewish Hospital and Medical Center of Brooklyn. Presented at the 18th Annual Meeting of the Somatic Cell Genetics Conference, Tucson, Arizona, USA.

Received for publication 18 August 1981
}

to compare the length of the $\mathrm{Y}$ chromosome and to examine the racial differences. In the present communication, we ask whether racial differences in the length of the $Y$ chromosome are because of the nf or f segment. To our knowledge, this is the first reported study where this type of approach has been used to demonstrate heteromorphisms of the human $\mathrm{Y}$ chromosome using banding techniques.

\section{Materials and methods}

The 60 American blacks were all healthy and between the ages of 25 and 65. Data on 60 Caucasians are taken from our previous report. ${ }^{16}$ All subjects had negative medical histories and were unrelated. The length of the $\mathrm{Y}$ chromosome was not known at the time of selection for the study. All chromosome preparations were made from cultured peripheral blood. ${ }^{19}$ QFQ technique was carried out 3 to 7 days after harvesting. QFQ cells were photographed on Tri-X Pan film using a Zeiss Photomicroscope II. ${ }^{20} 21$ At least 20 to 30 cells were photographed from each person with more than 3000 cells photographed from two populations. 
The five best differentiated cells were selected from each subject. Chromosomes were measured directly from the negative as there is a considerable amount of information lost during printing. Cells were projected by Simmon Omega Point Light Source Enlarger (Simmon Omega Inc, NY, USA: magnification $\times 8000)$. All chromosomes 19 and $20(F)$ were measured and the total $Y$ length, the fluorescent (f), and non-fluorescent (nf) segments were measured in the same cell. The value of $F$ was based on the average lengths of chromosomes 19 and 20. From these measurements, the ratios $Y / F, f / F$, and $\mathrm{nf} / \mathrm{F}$ were determined for each cell and the average was taken from five cells.

In order to determine the 'functional relationship' of one variable (for example, length of f segment vs total length of $Y$, etc) with another, a regression coefficient analysis was performed. A 'function' is a mathematical relation enabling us to predict what value of a variable $Y$ corresponds to given values of a variable $f$ etc. A $Y$ intercept (a) and regression coefficient (b) was calculated to determine the regression equation. A test of significance of regression coefficient was also performed. We also used correlation coefficient (r) analysis to examine the degree to which two variables vary together. Once established, such an association is likely to lead to reasoning about causal relationships between the variables. Test of significance and confidence limits for correlation coefficients were also calculated. ${ }^{22}$ The size distribution of the $Y$ chromosome length, which is partitioned into five classes for the frequency data in table 1 , was tested by $2 \times \mathrm{N}$ contingency $\chi^{2}$ test between two populations. Further, analysis of variance was used to test the significance of $\mathrm{nf}$ and $\mathrm{f}$ segments.

\section{Results and discussion}

We have suggested earlier that the length of the human $Y$ chromosome should be classified into at least five classes, namely, very small, small, average, large, and very large. ${ }^{16}$ The most frequent class was called average while the least frequent classes were

TABLE 1 Classification of $Y / F$ indices from 60 normal Caucasians and 60 normal American blacks*

\begin{tabular}{|c|c|c|c|c|c|}
\hline \multirow{2}{*}{$\begin{array}{l}\text { Criteria } \\
\text { (Y/Findex })\end{array}$} & \multirow[t]{2}{*}{ Size } & \multicolumn{2}{|c|}{ Caucasianst } & \multicolumn{2}{|c|}{ American blacks } \\
\hline & & $N o$ & $\%$ & No & $\%$ \\
\hline $\begin{array}{c}<\quad 0.80 \\
0.81-0.94 \\
0.95-1.09 \\
1.10-1.23 \\
>\quad 1.23\end{array}$ & $\begin{array}{l}\text { Very small } \\
\text { Small } \\
\text { Average } \\
\text { Large } \\
\text { Very large }\end{array}$ & $\begin{array}{r}0 \\
9 \\
40 \\
8 \\
3\end{array}$ & $\begin{array}{r}0 \\
15 \cdot 0 \\
66 \cdot 7 \\
13 \cdot 3 \\
5 \cdot 0\end{array}$ & $\begin{array}{r}0 \\
2 \\
34 \\
18 \\
6\end{array}$ & $\begin{array}{r}0 \\
3 \cdot 33 \\
56 \cdot 67 \\
30 \cdot 00 \\
10 \cdot 00\end{array}$ \\
\hline
\end{tabular}

*The length distribution is significantly different $(p<0.05)$.

tData from Verma et al. 16 called very small or very large. The frequercy distribution of the $\mathrm{Y} / \mathrm{F}$ index within each class is given in table 1 . Only $3.33 \%$ of American blacks had a small $\mathrm{Y}$, while this class occurred in $15 \%$ of Caucasians. The frequency of the large and very large classes was twice as high in blacks compared to Caucasians. The distribution of $\mathrm{Y} / \mathrm{F}$ indices of the five classes is shown in fig 1 and it is clearly demonstrated that a normal distribution of $\mathrm{Y} / \mathrm{F}$ indices was noted among Caucasians while the black population showed a skewed curve (skewed to the left). Consequently, to compare the average length of the $\mathrm{Y}$ chromosome $(1.02 \pm 0.09$ vs $1.09 \pm 0.10)$ (table 2) between the two populations is meaningless. However, employing $2 \times \mathrm{N}$ contingency $\chi^{2}$ test, the distribution of $Y$ lengths in both populations is significantly different $\left(\chi^{2}=10.972, \mathrm{p}<0.05\right)$.

To examine the heteromorphisms of fluorescent (f) and non-fluorescent (nf) segments of the human $\mathrm{Y}$ chromosome, $\mathrm{f} / \mathrm{F}$ and $\mathrm{nf} / \mathrm{F}$ ratios were also calculated. If the $\mathrm{nf}$ segment of the $\mathrm{Y}$ chromosome

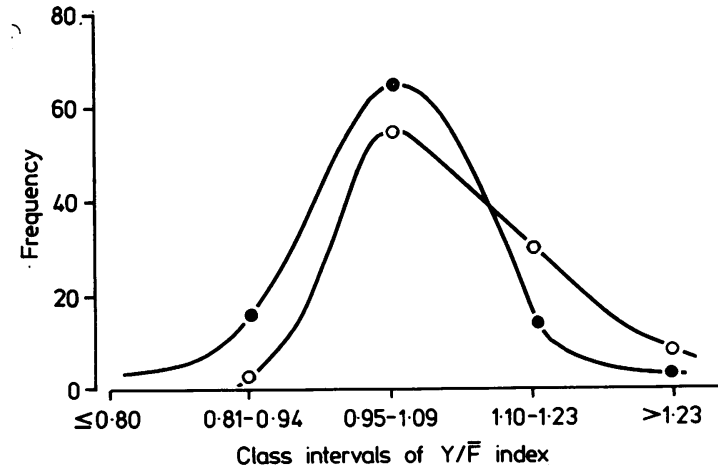

FIG 1 Distribution of $Y / F$ indices among Caucasians (solid dots) and among American blacks (open dots). The data are taken from table 1.

TABLE 2 Comparison of statistical parameters between Caucasians and American blacks

\begin{tabular}{lll}
\hline Component & Caucasians $^{*}$ & American blacks \\
\hline A & & \\
Mean & $1.02 \pm 0.09$ & $1.09 \pm 0.10$ \\
Y/F & $0.44 \pm 0.07$ & $0.42 \pm 0.09$ \\
nf/F & $0.57 \pm 0.04$ & $0.67 \pm 0.04$ \\
B Correlation (r) & & \\
f/F vs Y/F & 0.86 & 0.89 \\
nf/F vs Y/F & 0.63 & 0.53 \\
f/F vs nf/F & 0.26 & 0.22 \\
C Confidence limits & & \\
f/F vs Y/F & $0.9154-0.7818$ & $0.9329-0.8210$ \\
nf/F vs Y/F & $0.7616-0.3876$ & $0.6874-0.3131$ \\
f/F vs nf/F & $0.4831-0.0750$ & $0.4470-0.0385$ \\
\hline
\end{tabular}

*Data from Verma et al.16 


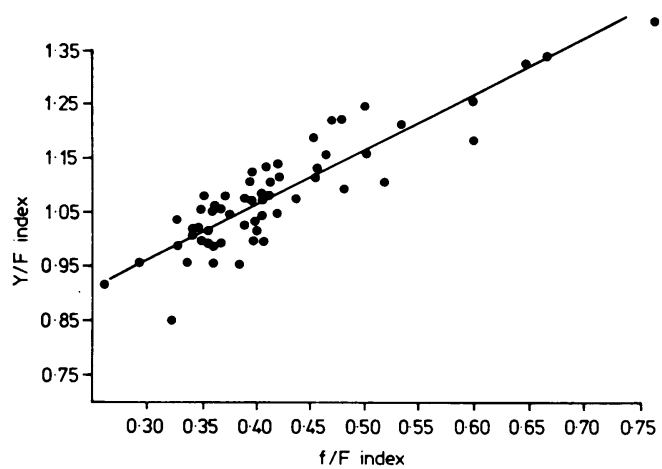

FIG 2 Length of the fluorescent segment of the $Y$ chromosome $(f / F)$ plotted against the length of the $Y$ chromosome $(Y / F)$. Regression line is also drawn.

is constant in size, then the nf/F ratio should not change, since the length of the $\mathrm{F}$ group chromosomes is constant. ${ }^{23}{ }^{24} \mathrm{~A}$ functional relationship between the two variables $(f / F$ vs $Y / F)$ was calculated by using regression coefficient analysis and a regression line was established (fig 2). A test of significance of the regression coefficient was also performed and it was concluded that a highly significant positive regression was present $(<0 \cdot 01)$. The correlation coefficient was also calculated and tested by the $t$ test. The correlation coefficient was 0.89 and the $95 \%$ confidence interval was computed to be 0.8210 to 0.9329 . It was found that there was significant correlation between $\mathrm{f} / \mathrm{F}$ and $\mathrm{Y} / \mathrm{F}$ indices $(p<0.01)$, that is the length of the $Y$ chromosome was significantly correlated with the length of the fluorescent segment. Similar statistics were computed for nf/F vs $\mathrm{Y} / \mathrm{F}$ and a similar conclusion was reached. The correlation coefficient was 0.53 $(p<0.01)$, with a confidence interval of 0.3131 to 0.6874 . The graphic plot is shown in fig 3. The correlation coefficient was also calculated for $\mathrm{f} / \mathrm{F}$

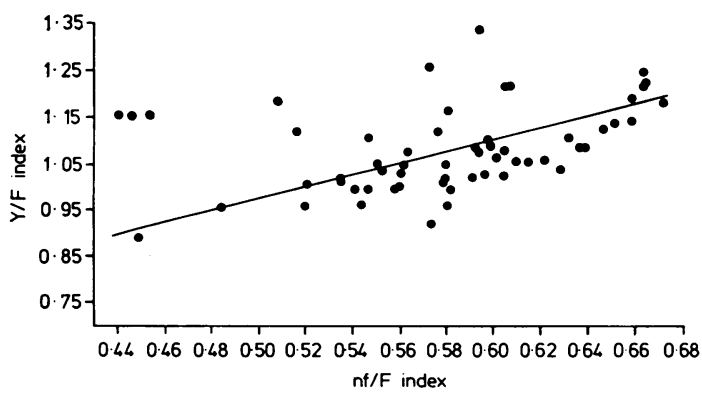

FIG 3 Length of the non-fluorescent segment of the $Y$ chromosome (nf/F) plotted against the length of the $Y$ chromosome $(Y / F)$. Regression line is also shown.

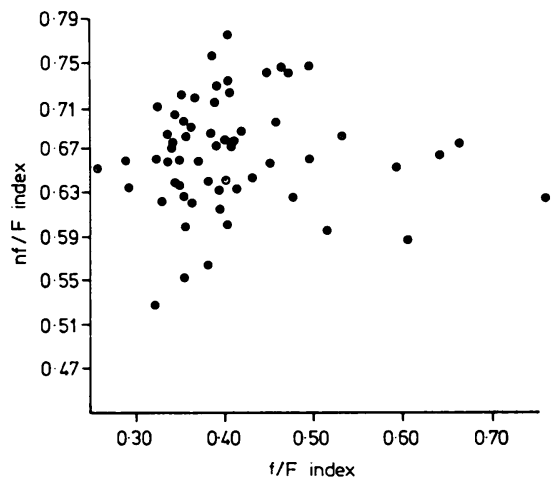

FIG 4 Length of the non-fluorescent segment of the $Y$ chromosome ( $n f / F)$ plotted against the length of the fluorescent segment $(f / F)$. No correlation was observed between these two parameters (see text).

vs $\mathrm{nf} / \mathrm{F}$ indices $(0 \cdot 22)$ and no significant relationship was observed $(p>0.05)$, that is, the $f$ and $n f$ segments vary independently and there was no relationship between them. A graphic plot is shown in fig 4. The mean $\mathrm{f} / \mathrm{F}$ and $\mathrm{nf} / \mathrm{F}$ indices were $0.42 \pm 0.09$ and $0.67 \pm 0.04$, respectively. Analysis of variances were also performed to test the difference.

Our findings indicate that the length of the $Y$ chromosome is dependent on the nf as well as the $f$ segments. Thus, both segments account for an increase in the size of the Y. These findings are contrary to the earlier view that the fluorescent segment accounts for the size variation of the $\mathrm{Y}$ chromosome while the non-fluorescent region is stable. ${ }^{9}$ No relationship between the size of the $\mathrm{f}$ and $\mathrm{nf}$ segments was observed, that is, they varied independently. Similar situations were noted in the Caucasian population. ${ }^{16}$ The longer $Y$ in the black population resulted from a longer non-fluorescent segment $(0.57$ vs $0.67 ; \mathrm{p}<0.05)$ as can be seen in table 2 . This finding is quite surprising since the nf segment was believed to be constant. ${ }^{9}$

It seems only logical that if chromosomal heteromorphisms are to be tolerated by a species, they would be likely to appear in that chromosome which is the least active genetically and whose loss would not be lethal. Both these criteria are fulfilled by the human $\mathrm{Y}$ chromosome. In man, only two genes have been assigned to the $\mathrm{Y}$ chromosome. ${ }^{25}$ The TDF (testis determining factor) is located on the short arm while the HY (Y histocompatibility antigen) gene is located in the non-fluorescent (nf) segment of the long arm of the chromosome. This raises the question of whether the size of the nf segment has any phenotypic effect, especially when 
it is either too long or too short. The present study suggests that variable $\mathrm{nf}$ and $\mathrm{f}$ segments do not have any phenotypic effects. The heteromorphic size of the long arm of the $Y$ chromosome is generally thought to be the result of deletion. ${ }^{26-29}$ Muldal and Ockey ${ }^{27}$ came to this conclusion because of the lack of the distal portion of the $Y$ chromosome. Wahlstrom ${ }^{30}$ observed that extremely short $\mathrm{Y}$ chromosomes did not fluoresce brightly at their distal end by the QFQ banding technique. There is sufficient evidence to conclude that the brighter segment contains a large amount of repetitive $\mathrm{DNA}^{31-33}$ and size variation in this segment (f) could be a repeat in a tandem arrangement. The mechanism generating length variation of the $\mathrm{nf}$ segment is at present unclear.

The biological significance of variation in the length of the $\mathrm{Y}$ chromosome is not clear. The observed group differences might indeed represent true chromosomal heteromorphisms, but the factor maintaining these heteromorphisms in the population is not known. Lubs and Patil ${ }^{34}$ suggested that there exists a north/south gradient in the length of $Y$ in Europeans, so that men of Mediterranean origin had a longer Y. Furthermore, some investigators have found a longer $Y$ in criminals, ${ }^{35}$ while others have not found any length differences between criminals and non-criminal controls. ${ }^{36}{ }^{37}$ It has also been suggested that long $\mathrm{Y}$ chromosomes may be an important cause of fetal loss. ${ }^{38} \mathbf{3 9}$

The present study has clearly demonstrated that the longer $\mathbf{Y}$ chromosome in American blacks is because of the $\mathrm{nf}$ segment. Future investigation of $\mathrm{Y}$ chromosomal abnormalities should attempt to determine if variation in the $\mathrm{nf}$ segment plays a role in the abnormalities. It has also been demonstrated that the length of the $Y$ chromosome is skewed in blacks, while normal distribution was noted among Caucasians. These findings make it possible for a more sophisticated analysis of the clinical significance of long Y chromosomes. Similarly, measurements might help to resolve the conflicting findings, for example, if certain clinical parameters were found to be more closely correlated with increased $\mathrm{nf}$ material than with $\mathrm{f}$ material or the total length. Further, this study provides the measurement data on $\mathrm{nf}$ and $\mathrm{f}$ segments in normal populations to compare with other normal as well as abnormal populations.

\section{References}

1 Denver Conference. A proposed standard system of nomenclature of human mitotic chromosomes. Lancet $1960 ; \mathbf{i}: 1063-5$.

2 Makino S, Muramoto T. Some observations on the variability of the human Y chromosome. Proc Jpn Acad 1964;40:757-61.
${ }^{3}$ Bishop A, Blank CE, Hunter H. Heritable variation in the length of the Y chromosome. Lancet 1962;ii:18-20.

4 de la Chapelle A, Hortling H, Edgren J, Kaariainen R. Evidence for existence of heritable large $Y$ chromosomes unassociated with developmental disorder. A cytogenetical and clinical study of four males with hypogonadism, one with mongolism and their relatives. Hereditas 1963;50:351-60.

5 Gripenberg U. Size variation and orientation of the human Y chromosome. Chromosoma 1964;15:618-29.

6 Unnerus U, Fellman J, de la Chapelle A. The length of the human Y chromosome. Cytogenetics 1967;6:213-27.

7 Borgaonkar DS, McKusick VA, Herr HM, de los Cobos L, Yoder OC. Constancy of the length of human $Y$ chromosome. Ann Genet (Paris) 1969;12:262-4.

${ }^{8}$ McKenzie WH, Hostetter TL, Lubs HA. Y family study: heritable variation in the length of the human $\mathrm{Y}$ chromosome. Am J Hum Genet 1972;24:686-93.

9 Bobrow M, Pearson PL, Pike MC, El-Alfi OS. Length variation in the quinacrine-banding segment of different size. Cytogenetics $1971 ; 10: 190-8$.

10 Laberge C, Gagne R. Quinacrine mustard staining solves the length variations of the human $\mathrm{Y}$ chromosome. Johns Hopkins Med J 1971;128:79-83.

11 Robinson JA, Buckton KE. Quinacrine fluorescence of variant and abnormal human $\mathrm{Y}$ chromosome. Chromosoma $1971 ; 35: 340-2$.

12 Knuntila S, Gripenberg V. The fluorescence pattern of a human Yq + chromosome. Hereditas 1972;70:307-8.

13 Nielsen J, Friedrich V. Length of the $Y$ chromosome in criminal males. Clin Genet 1972;3:281-5.

14 Schnedl W. Fluoreszenzunterschungen Uber die Langeuariabiliatat des Y-chromosomes beim Menschen. Hum Genet $1971 ; 12: 188-94$.

15 Soudek D, Langmuir V, Stewart DJ. Variation in the non-fluorescent segment of long Y chromosome. Hum Genet 1973;18:285-90.

16 Verma RS, Dosik H, Scharf T, Lubs HA. Length heteromorphisms of fluorescent (f) and non-fluorescent (nf) segments of human $Y$ chromosome: classification, frequencies, and incidence in normal Caucasians. $J$ Med Genet 1978;15:277-81.

17 Cohen MM, Shaw MW, MacClure JW. Racial differences in the length of the human $\mathrm{Y}$ chromosome. Cytogenetics 1966;5:34-52.

18 ISCN (1978). An international system for human cytogenetic nomenclature. Birth Defects 1978;XIV:No 8.

19 Verma RS, Rubenstein CT, Dosik $\mathrm{H}$. Effect of $\mathrm{Co}_{2}$ on short term human lymphocyte culture in vitro. In Vitro 1977;13:806-7.

20 Verma RS, Lubs HA. A simple R banding technic. Am J Hum Genet 1975;27:110-7.

21 Verma RS, Dosik H. An improved method of photographing human fluorescent chromosomes. $J$ Microsc 1976;108:339-41.

22 Sokal RR, Rohlf FJ. Biometry: the principles and practice of statistics in biological research. San Francisco: Freeman, 1969.

23 Paris Conference (1971). Standardization in human cytogenetics. Birth Defects 1972;8: No 7.

24 Ledley RS, Lubs HA, Ruddle FH. Introduction to chromosome analysis. Compt Biol Med 1972;2:107-28.

25 McKusick VA, Ruddle FH. The status of the gene map of the human chromosomes. Science 1977;196:390-405.

${ }^{26}$ Conen PE, Bailey JD, Allemang WH, Thompson DW, Ezrin C. A probable partial deletion of the $Y$ chromosome in an intersex patient. Lancet $1961 ; 2: 294-5$. 
27 Muldal S, Ockey CH. Deletion of $\mathrm{Y}$ chromosome in a family with muscular dystrophy. $\mathrm{Br} \mathrm{Med} J$ 1962;i: 291-4.

28 Nakagome Y, Sasaik M, Matsui I, Kawazura M, Fukuyama Y. A mentally retarded boy with a minute $\mathrm{Y}$ chromosome. J Pediatr 1965;67:1163-7.

29 Genest P, Laberge C, Poty J, Gagne R, Bouchard M. Transmission d'un petit ' $Y$ ' durant onze generations dans une lignee familiale. Ann Genet (Paris) 1970;13:233-8.

30 Wahlstrom J. Are variations in the length of $\mathrm{Y}$ chromosome due to structural changes? Hereditas 1971;69: 125-8.

31 Pardue ML, Gall JG. Chromosomal localization of mouse satellite DNA. Science 1970;168:1356-8.

32 Arrighi FE, Hsu TC. Localization of heterochromatin in human chromosome. Cytogenetics 1971;10:81-6.

33 Yunis JJ, Rolda L, Yasmineh WG, Lee JC. Staining of satellite DNA in metaphase chromosome. Nature 1971; 231:532-3.

${ }^{34}$ Lubs HA, Patil SR. Mediterranean origin of long Y chromosomes in Caucasians. Am J Hum Genet 1975; 27:60A.

${ }^{35}$ Soudek D, Laraya P. Longer Y chromosome in criminals. Clin Genet 1974;6:225-9.

36 Benezech M, Noel B, Travers E, Mattei J. Conduite antisociale et longueur du chromosome Y. Hum Genet 1976;32:77-80.

37 Brogger A, Urdal T, Larsen FB, Lavik NJ. No evidence for a correlation between behaviour and the size of the $Y$ chromosome. Clin Genet 1977;11:349-58.

38 Patil SR, Lubs HA. A possible association of long $\mathrm{Y}$ chromosome and fetal loss. Hum Genet 1977; 35 233-5.

39 Nielsen J. Large $\mathrm{Y}$ chromosome $\left(\mathrm{Y}_{\mathrm{q}}+\right)$ and increased risk of abortion. Clin Genet 1978;13:415-6.

Requests for reprints to Dr Ram S Verma, Division of Cytogenetics, The Jewish Hospital and Medical Center of Brooklyn, 555 Prospect Place, Brooklyn, NY 11238, USA. 